\title{
Simultaneous determination of diphenylarsinic and phenylarsinic acids in amended soils by optimized solvent extraction coupled to HPLC-MS/MS
}

\author{
Meng Zhu ${ }^{\mathrm{a}, \mathrm{c}}$, Chen $\mathrm{Tu}^{\mathrm{a}}$, Haibo Zhang ${ }^{\mathrm{a}, \mathrm{c}}$, Yongming Luo ${ }^{\mathrm{a}, \mathrm{b}, \mathrm{c}, *}$, , Peter Christie ${ }^{\mathrm{b}}$ \\ ${ }^{a}$ Key Laboratory of Coastal Environmental Processes and Ecological Remediation, Yantai Institute of Coastal Zone Research, Chinese Academy of Sciences, Yantai 264003, China \\ ${ }^{\mathrm{b}}$ Key Laboratory of Soil Environment and Pollution Remediation, Institute of Soil Science, Chinese Academy of Sciences, Nanjing 210008, China \\ c University of Chinese Academy of Sciences, Beijing, 100039, China
}

\section{A R T I C L E I N F O}

\section{Article history:}

Received 6 March 2015

Received in revised form 29 July 2015

Accepted 22 August 2015

Available online $\mathrm{xxxx}$

\section{Keywords:}

Diphenylarsinic acid (DPAA)

Phenylarsinic acid (PAA)

High performance liquid chromatography-

tandem mass spectrometry (HPLC-MS/MS)

Matrix effects

Recoveries

\begin{abstract}
A B S T R A C T
A solvent extraction method coupled to high-performance liquid chromatography with tandem mass spectrometry detection (HPLC-MS/MS) was developed and validated for the simultaneous determination of soil diphenylarsinic acid (DPAA) and phenylarsinic acid (PAA). Several extraction solvents were evaluated with respect to the degree of soil extract-induced matrix effects and the recovery values for DPAA and PAA in the four studied soil matrices. Validation data showed that solvent extraction had a negligible impact on the accurate quantification of DPAA. In contrast, only with disodium hydrogen phosphate extraction did the method give both limited matrix effects (102-107\%) with a coefficient of variation $<3 \%(n=4)$ and efficient recoveries (77-109\%) at two spiking levels ( 20 and $50 \mathrm{mg} \mathrm{kg}^{-1}$ ) for PAA. The selection of an appropriate extractant was the approach to reduce matrix effects while guaranteeing satisfactory recoveries of soil DPAA and PAA. Chromatographic separation was completed in $37 \mathrm{~min}$ and the analytes were detected in positive mode using selected reaction monitoring. MS/MS operating conditions were optimized for both electrospray ionization (ESI) and atmospheric pressure chemical ionization (APCI) sources. Under optimal conditions the detection limit was 0.01 and $1.00 \mu \mathrm{g} \mathrm{L} \mathrm{L}^{-1}$ for DPAA and PAA. The method detection limits (MDLs) obtained ranged from 2.52 to $3.42 \mu \mathrm{gg}^{-1}$ for DPAA and from 0.23 to $0.33 \mathrm{mg} \mathrm{kg}^{-1}$ for PAA depending on the soil types, and the intraday and interday precision was less than $5 \%$ for both analytes at two different concentrations. The method was successfully applied for the simultaneous determination of DPAA and PAA in one-month aged soils, satisfactory recoveries $(>74.03 \%)$ were obtained for both analytes. The results show that the proposed solvent extraction method coupled to HPLC-MS/MS analysis can provide accurate and reliable determinations of DPAA and PAA in soil samples.
\end{abstract}

(C) 2015 Elsevier B.V. All rights reserved.

\section{Introduction}

Recently, diphenylarsinic acid (DPAA) and phenylarsinic acid (PAA) have increasingly gained attention due to their occurrence as chemical warfare agents at contaminated sites and their potential to generate public and environmental health concerns (Ishizaki et al., 2005; Nakamiya et al., 2013; Arao et al., 2009; Ochi et al., 2004). The main source of DPAA and PAA into the environment is aromatic arsenicals (AAs) such as Clark I (diphenylcyanoarsine) and Clark II (diphenychloroarsine), which were widely produced during World Wars I and II as chemical warfare agents. These agents were then simply buried underground or dumped in the sea in several areas of China (Deng and Evans, 1997). Clark I and Clark II can be converted to DPAA

* Corresponding author at: Key Laboratory of Coastal Environmental Processes and Ecological Remediation, Yantai, Institute of Coastal Zone Research, Chinese Academy of Sciences, Yantai 264003, China.

E-mail address: ymluo@yic.ac.cn (Y. Luo). via hydrolysis and oxidation/reduction processes (Haas et al., 1998) and further biodegraded to PAA by dephenylation (Maejima et al., 2011a). The widespread occurrence of DPAA and PAA in groundwater in Asian and European countries has been reported (Hanaoka et al., 2005; Daus et al., 2008). However, few reports of the occurrence of DPAA and PAA in the soil compartment are available in the published literature. Hence, in order to better evaluate the occurrence, fate and potential environmental risk of DPAA and PAA to the soil environment, the development of a reliable extraction and sensitive analytical method for the simultaneous determination of the two analytes in various soil matrices is urgently required.

The analysis of DPAA and PAA can be carried out by various analytical techniques, for instance, high-performance liquid chromatography-inductively coupled plasma mass spectrometry (HPLC-ICPMS) (Kinoshita et al., 2005; Guan et al., 2012), high-performance liquid chromatography-pulsed amperometric detection (HPLC-PAD) (Li et al., 2012) and a derivation method followed by gas chromatography mass spectrometry (GC-MS) (Hanaoka et al., 2005). All of the above techniques have some shortcomings, such as wide variability 
and lack of selectivity. By contrast, selective LC separation coupled with structural information makes HPLC-MS/MS a powerful quantitative and qualitative analytical technique for sensitive and selective detection of DPAA and PAA in a variety of soil matrices. Evaluating and eliminating matrix effects, which is defined as the suppression/ enhancement of ion efficiency of compounds by co-eluting impurities arising from endogenous soil constituents and exogenous pretreatment processes (Niessen et al., 2006), is crucial for establishing a reliable HPLC-MS/MS method. Unfortunately, the reported HPLCMS/MS method for determination of DPAA and PAA does not address the matrix effects issue.

The most direct method for dealing with matrix effects is to comprehensively improve the sample pretreatment procedure. Selective extraction procedure and cleanup strategies aimed at either improving extraction efficiency of analytes or reducing matrix interference by constituents such as humic acid and salts have received considerable attention in environmental sample analysis. Numerous studies have reported the use of advanced pre-treatment techniques such as solidphase extraction (SPE) and size-exclusion chromatography (Fang et al., 2010; Zheng et al., 2011), which are expensive and timeconsuming and are also associated with some risk of loss of analyte. Therefore, the development of a simple, cost-effective and highlyselective extraction procedure to assist in the accurate, selective and reliable HPLC-MS/MS quantification of both DPAA and PAA is of great importance.

The first objective of this study was to develop a selective method for simultaneous quantification of DPAA and PAA based on HPLC-MS/MS measurements. The second objective was to optimize solvent extraction for efficient recoveries of DPAA and PAA, but lower recoveries of coextracted interfering substances. Finally, the present work aimed to validate the developed method for simultaneous determination of DPAA and PAA in various long-term contaminated soil matrices.

\section{Materials and methods}

\subsection{Chemicals and standards}

A DPAA (97\%) reference standard was purchased from Wako Pure Chemical Ind. Ltd. (Osaka, Japan) and PAA from Aladdin Chemistry Co. Ltd. (Shanghai, China). HPLC-grade methanol and formic acid were obtained from Merck KGaA (Darmstadt, Germany). All other chemicals and solvents used were of analytical grade quality.

Standard stock solutions of DPAA or PAA at $200 \mathrm{mg} \mathrm{L}^{-1}$ were prepared by dissolving in a small amount of methanol and adding ultrapure water. A $100 \mathrm{mg} \mathrm{L}^{-1}$ mixed standard was prepared in water by mixing and diluting the individual standard stock solutions. The mixed standard solution was then diluted with water to give a series of working standards of $0.1-40 \mathrm{mg} \mathrm{L}^{-1}$. These working standards were then used for sample fortification and the preparation of standard curves. All standard solutions were sealed and stored at $4{ }^{\circ} \mathrm{C}$. Water used in the study was purified using a Cascada laboratory water system (New York, USA).

\subsection{Soils}

Four types of soil were selected for the method validation, as they are widely subject to chemical warfare agent leakage. An Orthic Acrisol and a Gleyic Acrisol were collected from the surface horizon $(0-15 \mathrm{~cm})$ of agricultural fields at the Ecological Experiment Station of Red Soil in Yujiang county, Jiangxi province. A Haplic Phaeozem was sampled from Changchun, Jilin province, and an Udic Luvisol from Nanjing, Jiangsu province. The soil types are given according to the FAO soil classification system (FAO-UNESCO, 1981). All soil samples were air dried, sieved and the fraction smaller than $2 \mathrm{~mm}$ was collected and stored at $4{ }^{\circ} \mathrm{C}$ until analysis. The main physico-chemical properties of the tested soils and the land-use patterns are given in Table 1.

\subsection{Preparation of spiked soils}

An aliquot of each dried and homogenized soil sample $(1.0 \pm 0.1 \mathrm{~g})$ passed through a $0.25 \mathrm{~mm}$ nylon sieve was accurately weighed into a $50 \mathrm{~mL}$ Teflon tube. Since none of the analytes was found in the soils studied, the unamended soils were used as blank soil samples, and were spiked at two concentration levels ( 20 and $50 \mathrm{mg} \mathrm{kg}^{-1}$ ) in triplicate by adding $0.5 \mathrm{~mL}$ of the appropriate concentration of standard solution containing DPAA and PAA. The tube was then shaken on a vortex mixer for $10 \mathrm{~min}$ to achieve homogeneity. Finally, the tube was left overnight under a nitrogen stream to evaporate the solvent, before analysis. In all cases, the concentrations of the analytes in the soil are reported on a dry weight basis.

\subsection{Solvent extraction}

Two types of solvent were selected as candidate extractants. Type 1 (alkaline) has been employed to extract DPAA (Li et al., 2012; Guan et al., 2013), including disodium hydrogen phosphate $\left(0.1 \mathrm{~mol} \mathrm{~L}^{-1}\right)$ and sodium hydroxide $\left(1 \mathrm{~mol} \mathrm{~L}^{-1}\right)$ in $50 \%$ methanol. Type 2 (acid) is commonly used for inorganic arsenic extraction (Kahakachchi et al., 2004; Alam et al., 2001) and includes $0.125 \mathrm{~mol} \mathrm{~L}^{-1}$ citric buffer (pH 3.1) and phosphate $\left(1 \mathrm{~mol} \mathrm{~L}^{-1}\right)$.

After aging of the soil samples, extractant was added at a soil-towater ratio of $1: 10(\mathrm{v} / \mathrm{v})$ and all tubes were sealed and shaken for $6 \mathrm{~h}$ at $180 \mathrm{rpm}$ at $25 \pm 1{ }^{\circ} \mathrm{C}$ in the dark. The resulting mixture was then separated by centrifuging at $3000 \mathrm{rpm}$ for $10 \mathrm{~min}$. The suspension from each tube was filtered through a $0.22 \mu \mathrm{m}$ polyethersulfone (PES) membrane prior to HPLC-MS/MS analysis. Blank soil samples were also extracted according to the same procedure to obtain blank soil extracts.

\subsection{Sample preparation}

Four sets were prepared to systematically evaluate the assay accuracy, matrix effects and recovery efficiencies.

Table 1

Physico-chemical properties of soil samples.

\begin{tabular}{|c|c|c|c|c|}
\hline Property & Orthic Acrisol & Gleyic Acrisol & Phaeozem & Luvisol \\
\hline Land-use patterns & Peanut field & Paddy soil & $\overline{\text { Corn field }}$ & $\overline{\text { Woodland }}$ \\
\hline $\begin{array}{l}\mathrm{pH}\left(\mathrm{H}_{2} \mathrm{O}\right) \\
\quad \text { Soil particle composition (\%) }\end{array}$ & 4.94 & 4.85 & 4.55 & 4.99 \\
\hline Clay $(<2 \mu \mathrm{m})$ & 17.4 & 18.3 & 10.4 & 12.8 \\
\hline Slit $(2-20 \mu \mathrm{m})$ & 31.2 & 26.5 & 30.8 & 43.0 \\
\hline Sand $(20-200 \mu \mathrm{m})$ & 51.4 & 55.2 & 58.8 & 44.2 \\
\hline Total As ( $\left.\mathrm{mg} \mathrm{kg}^{-1}\right)$ & 16.1 & 11.2 & 14.1 & 13.2 \\
\hline DCB-extractable $\mathrm{Fe}_{2} \mathrm{O}_{3}\left(\mathrm{~g} \mathrm{~kg}^{-1}\right)^{\mathrm{a}}$ & 37.3 & 20.5 & 11.5 & 19.5 \\
\hline DCB-extractable $\mathrm{Al}_{2} \mathrm{O}_{3}\left(\mathrm{~g} \mathrm{~kg}^{-1}\right)^{\mathrm{a}}$ & 7.4 & 6.3 & 4.3 & 4.4 \\
\hline Organic matter (\%) & 1.23 & 3.86 & 2.98 & 1.68 \\
\hline
\end{tabular}

\footnotetext{
a DCB: dithionite-citrate-sodium bicarbonate.
} 
Table 2

Optimized MS/MS parameters for the analysis of the analytes by SRM in ESI mode.

\begin{tabular}{|c|c|c|c|c|c|}
\hline \multicolumn{6}{|l|}{ SRM } \\
\hline Analyte & Precursor & $\begin{array}{l}\text { Precursor } \\
\mathrm{m} / \mathrm{z}\end{array}$ & $\begin{array}{l}\text { Productor } \\
\mathrm{m} / \mathrm{z}\end{array}$ & $\begin{array}{l}\mathrm{CE} \\
(\mathrm{eV})^{\mathrm{a}}\end{array}$ & $\begin{array}{l}\text { TLO } \\
(\mathrm{eV})^{\mathrm{b}}\end{array}$ \\
\hline \multirow[t]{2}{*}{ DPAA } & {$[\mathrm{M}+\mathrm{H}]^{+}$} & 263.1 & 245.1 & 18 & 71 \\
\hline & {$[\mathrm{M}+\mathrm{H}]^{+}$} & 263.1 & 141.1 & 26 & 71 \\
\hline \multirow[t]{2}{*}{ PAA } & {$[\mathrm{M}+\mathrm{H}]^{+}$} & 203.2 & 91.3 & 33 & 64 \\
\hline & {$[\mathrm{M}+\mathrm{H}]^{+}$} & 203.2 & 77.4 & 45 & 64 \\
\hline \multicolumn{6}{|c|}{ MS/MS parameters } \\
\hline \multicolumn{3}{|c|}{ Discharge current $(\mu \mathrm{A})$} & \multicolumn{3}{|l|}{7.0} \\
\hline \multicolumn{3}{|c|}{ Capillary temperature $\left({ }^{\circ} \mathrm{C}\right)$} & \multicolumn{3}{|l|}{300} \\
\hline \multicolumn{3}{|c|}{ Vaporizer temperature $\left({ }^{\circ} \mathrm{C}\right)$} & \multicolumn{3}{|l|}{105} \\
\hline \multicolumn{3}{|c|}{ Collision gas } & \multicolumn{3}{|l|}{ Argon } \\
\hline \multicolumn{3}{|c|}{ Sheath gas } & \multicolumn{3}{|l|}{ Nitrogen } \\
\hline \multicolumn{3}{|c|}{ Sheath gas pressure $(\operatorname{arb})^{c}$} & \multicolumn{3}{|l|}{30} \\
\hline \multicolumn{3}{|c|}{ Dwell time (s) } & \multicolumn{3}{|l|}{30} \\
\hline
\end{tabular}

a $\mathrm{CE}$ : collision energy potential.

b TLO: tube lens offset.

c $\operatorname{arb}=$ arbitrarry.

Set 1 One standard line was prepared in pure solution (i.e. without matrix). Preliminary work showed that an appropriate $\mathrm{pH}$ was important to achieve good chromatographic separation, especially of PAA. As such, $100 \mu \mathrm{L}$ of appropriate standard solution containing analytes and $900 \mu \mathrm{L}$ \% formic acid (total volume $1 \mathrm{~mL}$ ) were added to $2 \mathrm{~mL}$ vials to obtain a series of working standards of $0.01,0.08,0.2,0.4,1.0 \mathrm{mg} \mathrm{L}^{-1}$.

Set 2 Sixteen standard lines were constructed in four different lots of blank soil extracts (spiked after extraction) when extracted with four solvents, respectively. $40 \mu \mathrm{L}$ of blank soil extracts with $60 \mu \mathrm{L}$ of appropriate standard mixture were pipetted into $2 \mathrm{~mL}$ vials, then diluted with $3 \%$ formic acid (total volume $1 \mathrm{~mL}$ ) to yield a series of working standards of 0.01-1.0 $\mathrm{mg} \mathrm{L}^{-1}$ (1:25 sample dilution ratio).

Set 3 Samples for the recovery experiment were prepared as described above in Sections 2.5 and 2.6 (spiked before extraction). A
$40 \mu \mathrm{L}$ aliquot of the soil extracts and $60 \mu \mathrm{L}$ of ultrapure water were pipetted into a $2 \mathrm{~mL}$ vial, diluted with $3 \%$ formic acid (total volume $1 \mathrm{~mL}$ ), then injected directly into the HPLC-MS/MS system.

Set 4 Four standard lines were constructed in four extractants by placing $40 \mu \mathrm{L}$ of extractant, $60 \mu \mathrm{L}$ of appropriate mixed standard and $900 \mu \mathrm{L}$ of $3 \%$ formic acid (total volume $1 \mathrm{~mL}$ ) in $2 \mathrm{~mL}$ vials to yield a series of working standards of $0.01-1.0 \mathrm{mg} \mathrm{L}^{-1}$.

\subsection{HPLC-MS/MS analysis}

Samples were analyzed using a HPLC system (Thermo Accela 1250, Thermo Fisher Scientific, San Jose, CA) equipped with MS/MS analyzer (Thermo TSQ Quantum Access Max, Thermo Fisher Scientific, San Jose, CA) using the external standard method. The analytical column was a Sunfire $\mathrm{C}_{18} 3.5 \mu \mathrm{m}, 2.1 \mathrm{~mm} \times 150 \mathrm{~mm}$ column (Waters, Milford, USA) protected by a Sunfire $C_{18} 3.5 \mu \mathrm{m}, 2.1 \mathrm{~mm} \times 10 \mathrm{~mm}$ guard column (Waters, Milford, USA). The temperature of the oven was maintained at $30^{\circ} \mathrm{C}$. The sample injection volume was $25 \mu \mathrm{L}$. Separation was carried out using a gradient solvent system at a flow rate of $0.15 \mathrm{~mL} \mathrm{~min}^{-1}$. Eluent $A$ consisted of $0.1 \%$ formic acid prepared in ultrapure water, eluent $B$ was $0.1 \%$ formic acid prepared in methanol. The gradient profile was as follows: $0-1.5 \min 1 \% \mathrm{~B}, 1.5-4 \min 1-25 \% \mathrm{~B}, 4-11 \min 25 \% \mathrm{~B}$, 11-15 min $25-70 \% \mathrm{~B}, 15-22 \min 70 \% \mathrm{~B}, 22-37 \min 1 \% \mathrm{~B}$. The flow rate was $0.150 \mathrm{~mL} \mathrm{~min}^{-1}$. The auto sampler temperature was set to $4{ }^{\circ} \mathrm{C}$ to stabilize the samples during time-consuming analyses. This LC separation method was modified from a previously reported HPLC separation technique (Baba et al., 2008).

Mass spectrometric detection was operated in positive mode with an electrospray ionization (ESI) source and an atmospheric-pressure chemical ionization (APCI) source. MS/MS parameters were optimized for each ionization source. Xcalibur 2.0 software (Thermo Fisher Scientific, San Jose, CA) was used for instrument control, data acquisition and data handling.

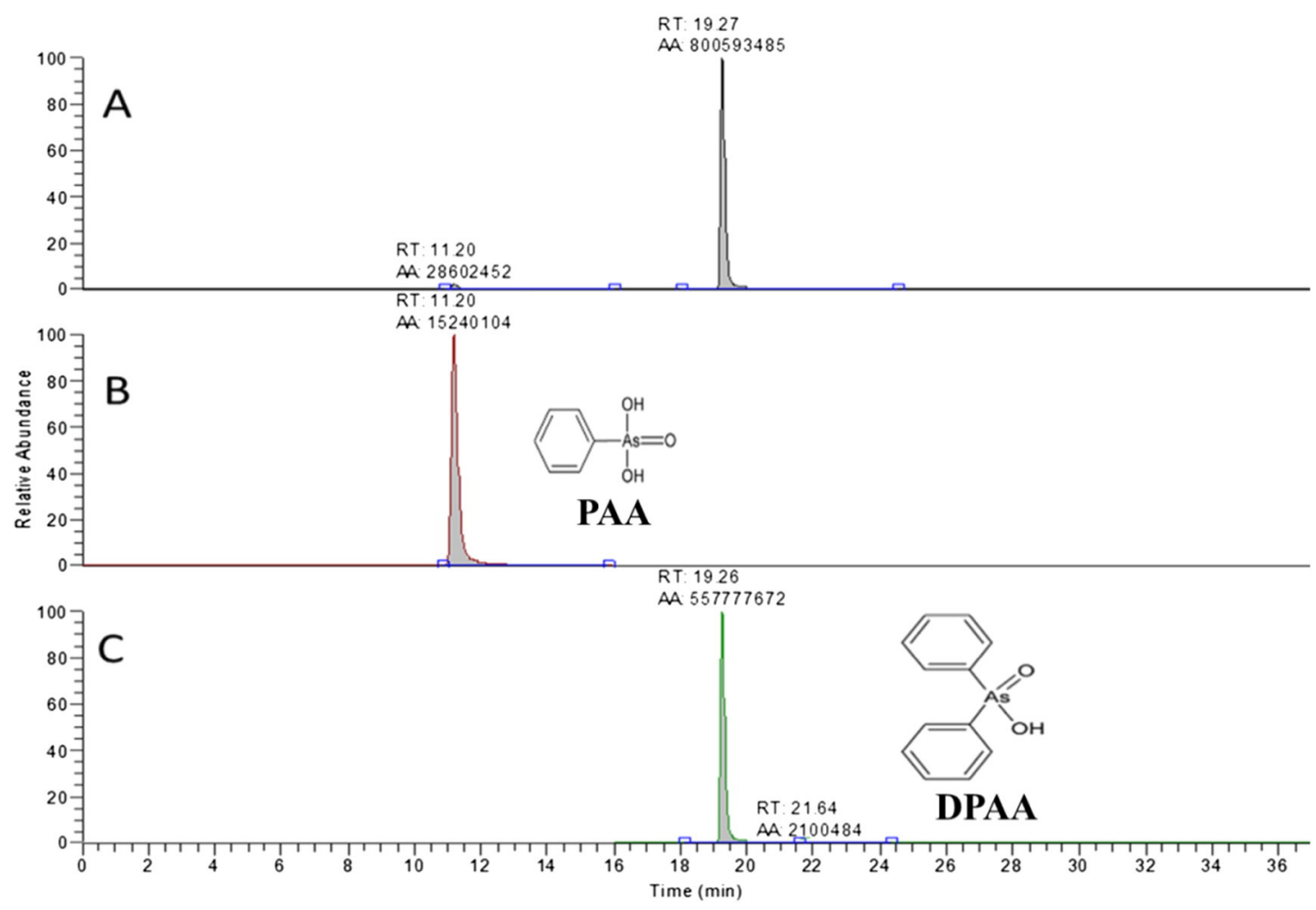

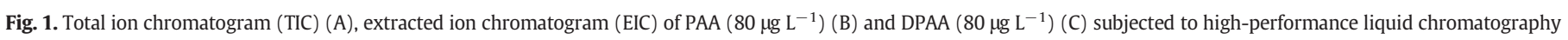
coupled with electrospray ionization tandem mass spectrometry (HPLC-ESI-MS/MS) analysis. 


\subsection{Method parameters}

In order to optimize the extractant, matrix effects (ME) and recovery efficiencies (RE) were considered and calculated by Eqs. (1) and (2), respectively.

$\operatorname{ME}(\%)=k_{\text {set } 2} / k_{\text {set1 }} \times 100$

$\operatorname{RE}(\%)=A_{\text {set } 3} / A_{\text {set2 }} \times 100$

Where, $k_{\text {set } 1}$ is the slope of conventional standard line constructed in pure solution in set $1, k_{\text {set } 2}$ is the slope of soil extract-matched standards in set $2, A_{\text {set }} 3$ is the absolute peak area of analyte in soil extracts spiked before extraction in set 3 , and $A_{\text {set } 2}$ is the absolute peak area of analyte in soil extracts spiked after extraction in set 2. Values of ME greater or less than $100 \%$ indicate matrix-induced signal enhancement or suppression.

\section{Results and discussion}

\subsection{Optimization of MS/MS conditions}

ESI remains the interface of choice for many environmental applications, in this sense, MS/MS operating conditions were optimized in ESI mode. To obtain higher selectivity, selected reaction monitoring (SRM) in positive-ion mode was chosen. The most intense precursor ion/product ion was used for DPAA and PAA quantification as shown in Table 2. The optimized MS/MS parameters and SRM conditions are presented in Table 2. Typical total ion chromatogram (TIC) and extracted ion chromatograms (EIC) of both analytes in HPLC-MS/MS analysis are shown in Fig. 1, indicate that a very good liquid-phase separation efficiency was obtained. Additionally, since most studies have demonstrated that APCI is less matrix sensitive that ESI (Chen et al., 2014; Zuehlke et al., 2004), MS/MS parameters were also optimized for APCI. However, APCI was discarded for further determinations due to the lower instrumental response to both analytes and the narrow linear range especially for PAA (data not shown).

\subsection{Selection of an appropriate extractant for matrix effects calibration}

The selection of an appropriate extractant is crucial to minimize both the matrix effects induced by the extractant itself and those induced by the co-extracted soil impurities because the content and the composition of impurities in the extracts is partially extractant-dependent. In the optimization of the extractant, several parameters need to be considered such as the type and the $\mathrm{pH}$ value of the extractant. In this work, the effect of four extractants with $\mathrm{pH}$ ranging from strongly

Table 3

Statistics from the regression analysis (regression line $\mathrm{y}=\mathrm{ax}+\mathrm{b})^{\mathrm{a}}$ of calibration data for DPAA. ${ }^{\mathrm{e}}$

\begin{tabular}{|c|c|c|c|c|c|c|}
\hline & $r^{2}$ & Slope & Intercept & $\operatorname{ME}(\%)^{\mathrm{b}}$ & $\mathrm{ME}_{\mathrm{E}}(\%)^{\mathrm{c}}$ & $\mathrm{CV}(\%)^{\mathrm{d}}$ \\
\hline \multicolumn{7}{|l|}{ Extractant 1 (disodium hydrogen phosphate) } \\
\hline Conventional calibration standard (set 1 ) & 0.9926 & $5.35 \mathrm{E}+08^{* *}$ & $2.88 \mathrm{E}+07$ & & & - \\
\hline \multicolumn{7}{|l|}{ Soil extract-matched standards(set 2 ) } \\
\hline Orthic Acrisol & 0.9944 & $6.16 \mathrm{E}+08$ & $2.97 \mathrm{E}+07$ & 115 & & 2.93 \\
\hline Gleyic Acrisol & 0.9987 & $5.89 \mathrm{E}+08$ & $2.58 \mathrm{E}+07$ & 110 & & \\
\hline Phaeozem & 0.9917 & $5.74 \mathrm{E}+08$ & $2.58 \mathrm{E}+07$ & 107 & & \\
\hline Luvisol & 0.9952 & $5.88 \mathrm{E}+08$ & $3.33 \mathrm{E}+07$ & 110 & & \\
\hline Extractant-matched standard (set 4) & 0.9937 & $5.51 \mathrm{E}+08^{* *}$ & $-1.65 \mathrm{E}+07$ & & 103 & - \\
\hline \multicolumn{7}{|l|}{ Extractant 2 (sodium hydroxide-methanol) } \\
\hline Conventional calibration standard (set 1 ) & 0.9926 & $5.35 \mathrm{E}+08$ & $2.88 \mathrm{E}+07$ & & & - \\
\hline \multicolumn{7}{|l|}{ Soil extract-matched standards (set 2) } \\
\hline Orthic Acrisol & 0.9958 & $5.46 \mathrm{E}+08$ & $2.01 \mathrm{E}+07$ & 102 & & 3.76 \\
\hline Gleyic Acrisol & 0.9988 & $5.54 \mathrm{E}+08$ & $1.65 \mathrm{E}+07$ & 104 & & \\
\hline Phaeozem & 0.9989 & $5.88 \mathrm{E}+08$ & $1.75 \mathrm{E}+07$ & 110 & & \\
\hline Luvisol & 0.9998 & $5.43 \mathrm{E}+08$ & $1.81 \mathrm{E}+07$ & 102 & & \\
\hline Extractant-matched standard (set 4) & 0.9979 & $4.75 \mathrm{E}+08^{* *}$ & $0.75 \mathrm{E}+07$ & & 89 & - \\
\hline \multicolumn{7}{|l|}{ Extractant 3 (citrate buffer) } \\
\hline Conventional calibration standard (set 1 ) & 0.9926 & $5.35 \mathrm{E}+08^{* *}$ & $2.88 \mathrm{E}+07$ & & & - \\
\hline \multicolumn{7}{|l|}{ Soil extract-matched standards (set 2) } \\
\hline Orthic Acrisol & 0.9974 & $5.69 \mathrm{E}+08$ & $1.25 \mathrm{E}+07$ & 106 & & 0.50 \\
\hline Gleyic Acrisol & 0.9991 & $5.66 \mathrm{E}+08$ & $1.06 \mathrm{E}+07$ & 106 & & \\
\hline Phaeozem & 0.9989 & $5.68 \mathrm{E}+08$ & $1.07 \mathrm{E}+07$ & 106 & & \\
\hline Luvisol & 0.9982 & $5.72 \mathrm{E}+08$ & $1.20 \mathrm{E}+07$ & 107 & & \\
\hline Extractant-matched standard (set 4) & 0.9988 & $5.80 \mathrm{E}+08^{* *}$ & $0.95 \mathrm{E}+07$ & & 108 & - \\
\hline \multicolumn{7}{|l|}{ Extractant 4 (phosphate) } \\
\hline Conventional calibration standard (set 1 ) & 0.9926 & $5.35 \mathrm{E}+08$ & $2.88 \mathrm{E}+07$ & & & - \\
\hline \multicolumn{7}{|l|}{ Soil extract-matched standards (set 2 ) } \\
\hline Orthic Acrisol & 0.9977 & $5.35 \mathrm{E}+08$ & $1.10 \mathrm{E}+07$ & 100 & & 3.04 \\
\hline Gleyic Acrisol & 0.9969 & $5.48 \mathrm{E}+08$ & $1.27 \mathrm{E}+07$ & 102 & & \\
\hline Phaeozem & 0.9964 & $5.65 \mathrm{E}+08$ & $1.21 \mathrm{E}+07$ & 106 & & \\
\hline Luvisol & 0.9993 & $5.28 \mathrm{E}+08$ & $1.01 \mathrm{E}+07$ & 99 & & \\
\hline Extractant-matched standard (set 4) & 0.9990 & $5.42 \mathrm{E}+08$ & $0.73 \mathrm{E}+07$ & & 101 & - \\
\hline
\end{tabular}

** Difference between the treatments (set 1 and set 2, set 4 and set 2 ) significant at the 0.01 probability level (independent-sample $t$ test).

$y$ is the absolute peak area of analyte, $x$ is the concentration of analyte.

b ME: matrix effects, ME expressed as the ratio of the slope of soil extracts-matched standards in set 2 to the slope of conventional calibration standard in set 1 multiplied by 100 . Values of greater or less than $100 \%$ indicate matrix-induced signal enhancement or suppression.

${ }^{\mathrm{C}} \mathrm{ME}_{\mathrm{E}}$ : extractant-induced matrix effects, $\mathrm{ME}_{\mathrm{E}}$ expressed as the ratio of the slope of extractant-matched standard in set 4 to the slope of conventional calibration standard in set 1 multiplied by 100 . Values of greater or less than $100 \%$ indicate extractant-induced signal enhancement or suppression.

d CV: coefficients of variation, CV calculated from slopes of soil extracts-matched calibration lines constructed in four different lots of blank soil extracts (Orthic Acrisol, Gleyic Acrisol, Phaeozem, Luvisol).

e In all cases HPLC-MS/MS has been used for separation and quantification. 
acidic to strongly alkaline on matrix effects was studied in a preliminary fashion to minimize the ion suppression/enhancement effect.

Matrix effects were assessed according to a strategy proposed by Matuszewski et al. (2003). As can be observed from the data summarized in Table 3, although the slopes of standards constructed in multiple soil extracts (set 2) deviated from that of conventional pure solution (set 1) for DPAA, this deviation had a negligible impact on the accuracy of the quantification of DPAA ( $85 \% \leq \mathrm{ME} \leq 115 \%$, coefficient of variation, $C V \leq 5 \%$ ). In contrast, only with disodium hydrogen phosphate extraction was a limited matrix effect $(102 \% \leq \mathrm{ME} \leq 107 \%$, $\mathrm{CV} \leq 3 \%$ ) obtained for PAA as presented in Table 4. The higher matrix tolerance of DPAA than of PAA may possibly be associated with the comparatively longer retention time of DPAA (19.3 min) than PAA (11.4 min), as sufficient chromatographic separation in the quantitative determination of analytes is recommended to avoid possible co-elution with interfering substances (Liang et al., 2003).

In order to investigate the influence on the MS response by the extractant itself, extractant-induced matrix effects $\left(\mathrm{ME}_{\mathrm{E}}\right)$ were studied and calculated as follows:

$\operatorname{ME}_{\mathrm{E}}(\%)=k_{\text {set } 4} / k_{\text {set } 1} \times 100$

where, $k_{\text {set }} 4$ is the slope of extractant-matched standard in set 4 , and $k_{\text {set } 1}$ is the slope of conventional standard constructed in pure solution in set 1 .
The results of $\mathrm{ME}_{\mathrm{E}}$ presented in Table 4 indicate that matrixinduced signal enhancement/suppression was both compounddependent and extractant-dependent as considerable signal suppression was observed for sodium hydroxide-methanol $\left(\mathrm{ME}_{\mathrm{E}}=\right.$ $55 \%$ ), which was at the utmost concentration and alkalinity compared with other extractants.

Previous work has indicated that large amounts of soluble salts introduced in the sample extraction procedure can induce methadone hydrochloride (MTD) signal suppression (Souverain et al., 2004). MTD eluted in the matrix effects window (with retention time less than $1 \mathrm{~min}$ ) is not consistent with the retention time of analytes in our experiment. Theoretically, soluble salts are eluted quickly from the column, diverted to waste prior to the MS analyzer, and will not cause the measured impact on MS/MS response. However, sodium hydroxidemethanol can react with PAA to form a salt, and finally may induce matrix effect as the salt may be co-desorbed and compete with the analyte molecules for the limited amount of charge per droplet in the ion emission process (Enke, 1997). Therefore, it may be inappropriate to apply strong alkalis (e.g. sodium hydroxide-methanol) as extractants for PAA prior to HPLC-MS/MS analysis.

Similarly, sodium hydroxide-methanol can also react with DPAA to form a salt, but decreased extractant-induced matrix suppression effects occurred for DPAA ( $\mathrm{ME}_{\mathrm{E}}=89 \%$ ). A possible explanation is that PAA is more vulnerable to alkaline salts due to its higher content of

Table 4

Statistics from the regression analysis (regression line $y=a x+b)^{a}$ of calibration data for PAA. ${ }^{e}$

\begin{tabular}{|c|c|c|c|c|c|c|}
\hline & $r^{2}$ & Slope & Intercept & $\begin{array}{l}\mathrm{ME} \\
(\%)^{\mathrm{b}}\end{array}$ & $\mathrm{ME}_{\mathrm{E}}(\%)^{\mathrm{c}}$ & $\begin{array}{l}\mathrm{CV} \\
(\%)^{\mathrm{d}}\end{array}$ \\
\hline \multicolumn{7}{|l|}{ Extractant 1 (disodium hydrogen phosphate) } \\
\hline Conventional calibration standard (set 1 ) & 0.9968 & $1.47 \mathrm{E}+07^{*}$ & $3.91 \mathrm{E}+05$ & & & - \\
\hline \multicolumn{7}{|l|}{ Soil extract-matched standards (set 2 ) } \\
\hline Orthic Acrisol & 0.9999 & $1.56 \mathrm{E}+07$ & $1.81 \mathrm{E}+05$ & 107 & & \multirow[t]{4}{*}{2.42} \\
\hline Gleyic Acrisol & 0.9997 & $1.49 \mathrm{E}+07$ & $2.79 \mathrm{E}+05$ & 102 & & \\
\hline Phaeozem & 0.9981 & $1.52 \mathrm{E}+07$ & $3.35 \mathrm{E}+05$ & 104 & & \\
\hline Luvisol & 0.9988 & $1.56 \mathrm{E}+07$ & $3.69 \mathrm{E}+05$ & 106 & & \\
\hline Extractant-matched standard (set 4) & 0.9988 & $9.98 \mathrm{E}+06^{* *}$ & $1.98 \mathrm{E}+05$ & & 68 & - \\
\hline \multicolumn{7}{|l|}{ Extractant 2 (sodium hydroxide-methanol) } \\
\hline Conventional calibration standard (set 1) & 0.9968 & $1.47 \mathrm{E}+07^{*}$ & $3.91 \mathrm{E}+05$ & & & - \\
\hline \multicolumn{7}{|l|}{ Soil extract-matched standards (set 2) } \\
\hline Orthic Acrisol & 0.9990 & $1.28 \mathrm{E}+07$ & $3.89 \mathrm{E}+05$ & 87 & & \multirow[t]{4}{*}{7.61} \\
\hline Gleyic Acrisol & 0.9991 & $1.29 \mathrm{E}+07$ & $2.46 \mathrm{E}+05$ & 88 & & \\
\hline Phaeozem & 0.9994 & $1.33 \mathrm{E}+07$ & $3.85 \mathrm{E}+05$ & 91 & & \\
\hline Luvisol & 0.9995 & $1.11 \mathrm{E}+07$ & $4.47 \mathrm{E}+05$ & 76 & & \\
\hline Extractant-matched standard (set 4) & 1.0000 & $8.06 \mathrm{E}+06^{* *}$ & $5.63 \mathrm{E}+04$ & & 55 & - \\
\hline \multicolumn{7}{|l|}{ Extractant 3 (citrate buffer) } \\
\hline Conventional calibration standard (set 1 ) & 0.9968 & $1.47 \mathrm{E}+07^{* *}$ & $3.91 \mathrm{E}+05$ & & & - \\
\hline \multicolumn{7}{|l|}{ Soil extract-matched standards (set 2) } \\
\hline Orthic Acrisol & 0.9987 & $1.28 \mathrm{E}+07$ & $3.89 \mathrm{E}+05$ & 87 & & \multirow[t]{4}{*}{4.87} \\
\hline Gleyic Acrisol & 0.9997 & $1.25 \mathrm{E}+07$ & $2.46 \mathrm{E}+05$ & 85 & & \\
\hline Phaeozem & 0.9993 & $1.23 \mathrm{E}+07$ & $3.85 \mathrm{E}+05$ & 84 & & \\
\hline Luvisol & 0.9975 & $1.14 \mathrm{E}+07$ & $4.47 \mathrm{E}+05$ & 78 & & \\
\hline Extractant-mathched standard (set 4) & 0.9998 & $1.18 \mathrm{E}+07$ & $5.63 \mathrm{E}+05$ & & 80 & - \\
\hline \multicolumn{7}{|l|}{ Extractant 4 (phosphate) } \\
\hline Conventional calibration standard (set 1 ) & 0.9968 & $1.47 \mathrm{E}+07^{* *}$ & $3.91 \mathrm{E}+05$ & & & - \\
\hline \multicolumn{7}{|l|}{ Soil extract-matched standards (set 2) } \\
\hline Orthic Acrisol & 0.9986 & $1.14 \mathrm{E}+07$ & $2.51 \mathrm{E}+05$ & 78 & & \multirow[t]{4}{*}{3.08} \\
\hline Gleyic Acrisol & 0.9992 & $1.18 \mathrm{E}+07$ & $2.62 \mathrm{E}+05$ & 80 & & \\
\hline Phaeozem & 0.9985 & $1.22 \mathrm{E}+07$ & $2.15 E+05$ & 83 & & \\
\hline Luvisol & 0.9996 & $1.15 \mathrm{E}+07$ & $2.14 \mathrm{E}+05$ & 78 & & \\
\hline Extractant-matched standard (set 4) & 0.9981 & $1.13 \mathrm{E}+07$ & $2.86 \mathrm{E}+05$ & & 77 & - \\
\hline \multirow{7}{*}{\multicolumn{7}{|c|}{$\begin{array}{l}\text { * Difference between the treatments (set } 1 \text { and set } 2 \text {, set } 4 \text { and set } 2 \text { ) significant at the } 0.05 \text { probability level (independent-sample } t \text { test). } \\
\text { ** Difference between the treatments (set } 1 \text { and set } 2 \text {, set } 4 \text { and set } 2 \text { ) significant at the } 0.01 \text { probability level (independent-sample } t \text { test). } \\
\text { a } y \text { is the absolute peak area of analyte, } x \text { is the concentration of analyte. } \\
\text { b ME: matrix effects, ME expressed as the ratio of the slope of soil extracts-matched standards in set } 2 \text { to the slope of conventional calibration standard in set } 1 \text { multiplied by } 100 \text {. Values } \\
\text { of greater or less than } 100 \% \text { indicate matrix-induced signal enhancement or suppression. } \\
\text { c ME } \text { ME }_{\mathrm{E}} \text { : extractant-induced matrix effects, } \mathrm{ME}_{\mathrm{E}} \text { expressed as the ratio of the slope of extractant-matched standard in set } 4 \text { to the slope of conventional calibration standard in set } 1 \\
\text { d CV: coefficients of variation, CV calculated from slopes of soil extracts-matched calibration lines constructed in four different lots of blank soil extracts (Orthic Acrisol, Gleyic Acrisol, }\end{array}$}} \\
\hline & & & & & & \\
\hline & & & & & & \\
\hline & & & & & & \\
\hline & & & & & & \\
\hline & & & & & & \\
\hline & & & & & & \\
\hline \multicolumn{7}{|c|}{$\begin{array}{l}\text { Phaeozem, Luvisol). } \\
\text { e In all cases HPLC-MS/MS has been used for separation and quantification. }\end{array}$} \\
\hline
\end{tabular}


hydroxyl-groups. When the sample $\mathrm{pH}$ was adjusted to the range 2.5-3.5 with $3 \%$ formic acid prior to HPLC-MS/MS detection, DPAA ( $\mathrm{pKa} 5.2$ ) was in molecular form in contrast with PAA $\left(\mathrm{pKa} \mathrm{a}_{1} 3.8\right.$, $\mathrm{pKa}_{2}$ 8.7).

The results show that the extractant alone cannot fully explain the observed matrix effects, as inferred by the substantial slope deviation between the soil extract-matched standard curve (set 2) and extractant-matched standard curve (set 4), especially for disodium hydrogen phosphate $(p<0.01)$ and sodium hydroxide-methanol $(p<0.01)$ as indicated in Table 4 . This might be partly due to the buffering capacity of the soil. As indicated in Table 4, the extractant itself (set 4 ) induced significant signal suppression for PAA (55\% $\leq \mathrm{ME} \leq 80 \%$ ), reducing the amount of soluble salts or sample $\mathrm{pH}$ in the extraction procedure due to adsorption or ion exchange processes on soil surfaces will alleviate matrix effects to some extent ( $M E \geq 76 \%$ ). On the other hand, some "unseen" and "undetected" matrix components, which may be several orders of magnitude higher than that of analytes, will also exist in extracts and severely affect the efficiency of formation of the desired molecular ions selected by the first quadrupole for further dissociation and quantification (Matuszewski et al., 1998).

Dissolved organic matter (DOM) induced matrix effects have received considerable attention in environmental sample analysis in recent years. The signal suppression by co-extracted humic acid, as indicated by a yellow color in methanol extracts, was studied by Steen et al. (1999). The yellow color was also observed in soil extracts with sodium hydroxide-methanol extraction in our experiment, particularly for Phaeozem/Gleyic Acrisol soil owing to higher SOM content.

Table 4 shows no increased matrix suppression effects when comparing the Phaeozem ( $\mathrm{ME}=91 \%$ )/Gleyic Acrisol ( $\mathrm{ME}=88 \%$ ) with the
Orthic Acrisol ( $\mathrm{ME}=87 \%) /$ Luvisol $(\mathrm{ME}=76 \%)$, despite their contrasting SOM contents. Similar results have been obtained by Steen et al. (1999) indicating that the degree of ion suppression depends partly on the amount of co-extracted DOM, and partly on the nature of the samples. Kloepfer et al. (2005) further demonstrated that the molecular weight distribution of organic material was crucial to matrix effects and this will complicate the situation.

\subsection{Recovery study}

Alkaline extractants gave excellent recoveries ( $R E>81 \%$ ) of analytes at two concentrations with only one exception according to Fig. 2. It may be proposed that at higher $\mathrm{pH}$ the arsenate groups on DPAA are anionic species, and the soil surface become negatively charged. This would facilitate desorption of DPAA or PAA onto the soil surfaces through van der Waals attraction (Wang et al., 2013).

As for soil type, high recoveries of DPAA (RE $>81 \%$ ) and PAA $(\mathrm{RE}>77 \%)$ in the Orthic Acrisol and Gleyic Acrisol at two concentrations were achieved regardless of extractants, while in the case of the Phaeozem/Luvisol, phosphate did not provide exhaustive extraction ( $37 \% \leq \mathrm{RE} \leq 59 \%$ ) of DPAA. This corresponds well with a recent study indicating that adsorption of DPAA was inhibited significantly by phosphate in an Acrisol but not in a Phaeozem (Wang et al., 2013). PAA in the Phaeozem/Luvisol was more likely to be extracted by phosphate, with an average recovery of $98.5 \%$, which might be due to the different partition coefficient $\left(\log K_{\text {ow }}\right.$ ) values. Although DPAA and PAA would have been adsorbed mainly onto Fe/Al oxyhydroxides, the phenyl groups of DPAA/PAA might be adsorbed onto SOM by hydrophobic interaction (Maejima et al., 2011b). Thus, PAA ( $\left.\log K_{\text {ow }} 0.30\right)$ seems

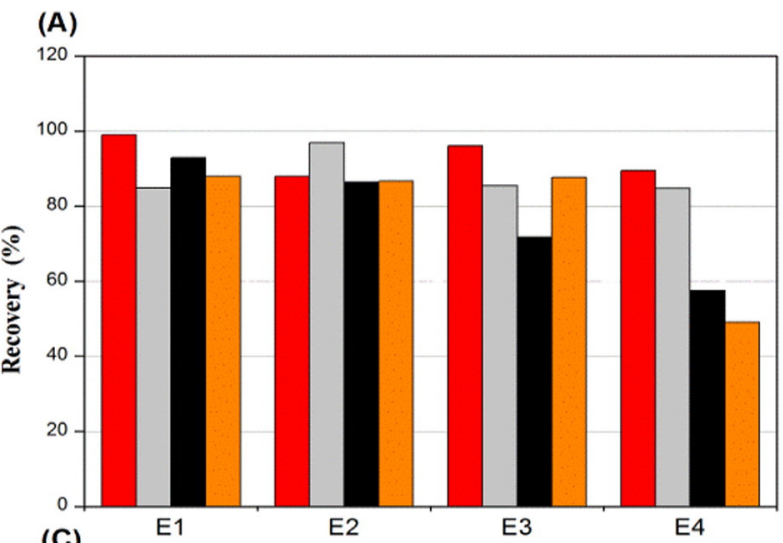

(B)

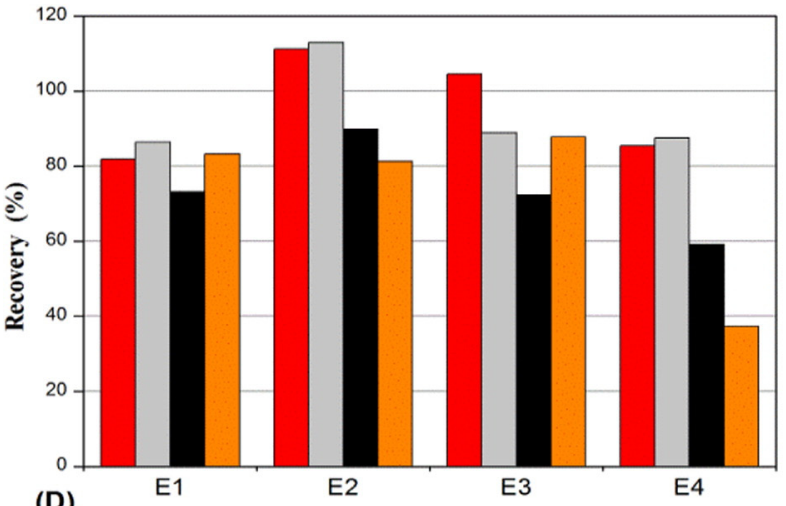

(D)
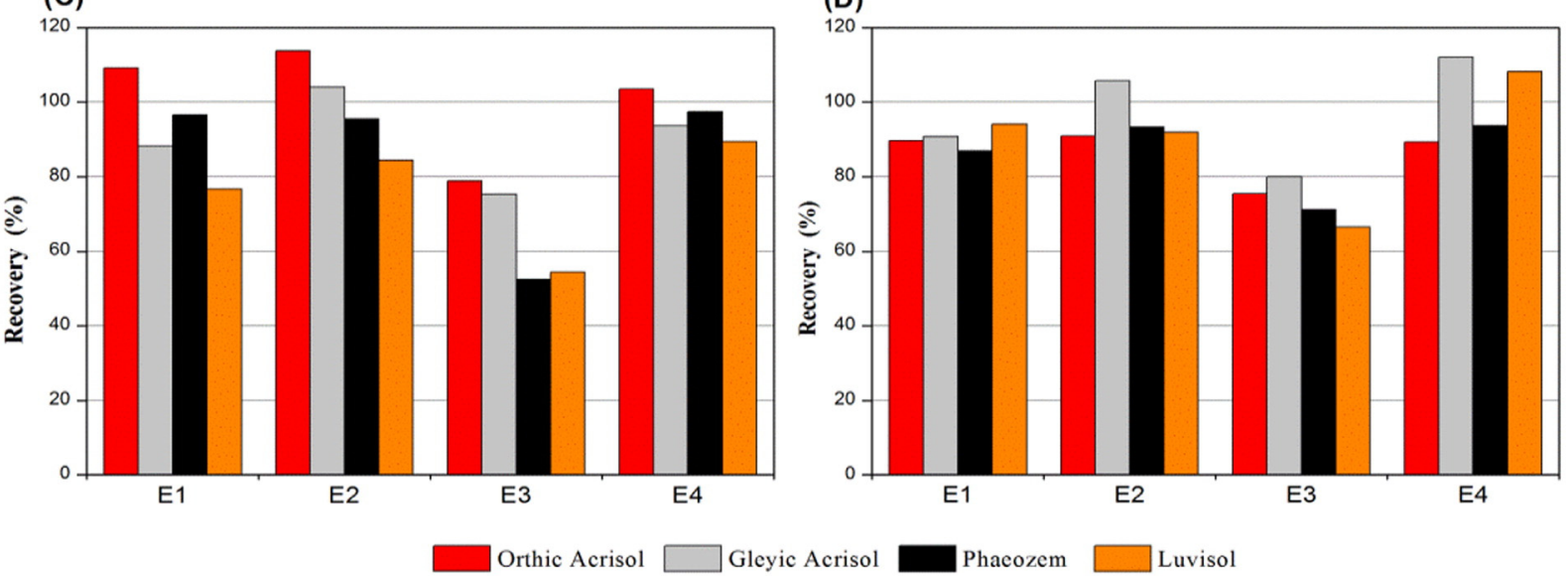

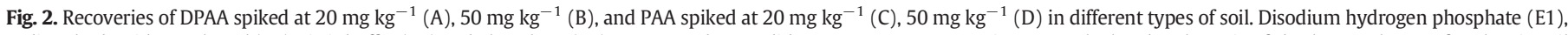

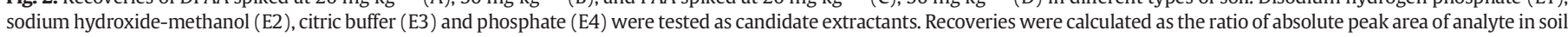
extract spiked before extraction to the ratio of absolute peak area of analyte in soil extract spiked after extraction, and expressed as mean of three parallel samples. 
Table 5

Analysis of soil spiked with a standard mix of two phenylarsinic acids.

\begin{tabular}{|c|c|c|c|c|c|}
\hline Analyte & & $\begin{array}{l}\text { Measured } \\
\left(\mathrm{mg} \mathrm{kg}^{-1}\right)^{\mathrm{b}}\end{array}$ & $\begin{array}{l}\text { Intra-day RSD } \\
(\%)^{c}\end{array}$ & $\begin{array}{l}\text { Inter-day RSD } \\
(\%)^{\mathrm{d}}\end{array}$ & $\begin{array}{l}\text { Accuracy } \\
(\%)^{\mathrm{e}}\end{array}$ \\
\hline \multirow[t]{3}{*}{ DPAA $\left(20 \mathrm{mg} \mathrm{kg}^{-1}\right)^{\mathrm{a}}$} & Day 1 & $20.9 \pm 0.5$ & 2.2 & 3.4 & 4.5 \\
\hline & Day 2 & $20.9 \pm 0.6$ & 2.8 & & 4.5 \\
\hline & Day 3 & $21.1 \pm 1.7$ & 5.0 & & 5.5 \\
\hline \multirow[t]{3}{*}{ DPAA $\left(50 \mathrm{mg} \mathrm{kg}^{-1}\right)^{\mathrm{a}}$} & Day 1 & $51.5 \pm 0.7$ & 1.3 & 2.0 & 3.0 \\
\hline & Day 2 & $52.1 \pm 0.9$ & 1.7 & & 4.2 \\
\hline & Day 3 & $52.0 \pm 1.5$ & 2.9 & & 4.0 \\
\hline \multirow[t]{3}{*}{ PAA $\left(20 \mathrm{mg} \mathrm{kg}^{-1}\right)^{\mathrm{a}}$} & Day 1 & $21.2 \pm 0.8$ & 3.7 & 2.9 & 6.0 \\
\hline & Day 2 & $21.4 \pm 0.8$ & 3.6 & & 7.0 \\
\hline & Day 3 & $21.2 \pm 0.3$ & 1.4 & & 6.0 \\
\hline \multirow[t]{3}{*}{ PAA $\left(50 \mathrm{mg} \mathrm{kg}^{-1}\right)^{\mathrm{a}}$} & Day 1 & $51.8 \pm 0.9$ & 1.8 & 2.5 & 3.6 \\
\hline & Day 2 & $51.2 \pm 1.1$ & 2.2 & & 2.4 \\
\hline & Day 3 & $52.4 \pm 1.7$ & 3.3 & & 4.8 \\
\hline
\end{tabular}

a Spiked concentration.

b Mean concentration \pm standard deviation, $n=4$.

c Intraday RSD: $n=5$, RSD (relative standard deviation) (\%) $=$ SD/average $\times 100$.

d Interday RSD: $n=5$ series per day for 3 days.

e Accuracy $(\%)=[($ measured value - theoretical value $) /$ theoretical value $] \times 100$.

to be less affected by the allocation of organic matter compared with DPAA, so that the former is more likely to desorb from soil surfaces in the presence of phosphate.

In addition, the citrate buffer showed moderate recoveries of DPAA $(72 \% \leq \mathrm{RE} \leq 105 \%)$ and PAA $(52 \% \leq \mathrm{RE} \leq 80 \%)$ in all four types of soil. Previous work has demonstrated that desorption of inorganic arsenic probably occurs in the presence of citrate through a complex mechanism involving competitive adsorption, dissolution of $\mathrm{Fe} / \mathrm{Al}$ oxides or oxyhydroxides (Mohapatra et al., 2005). Here, we suggest that Fe/Al oxide or oxyhydroxide- bonded DPAA/PAA can also be exchanged by a citrate buffer. The lower recovery of PAA observed was most probably due to more hydroxyl groups for PAA than DPAA. Based on the results described above, we suggest that several parameters including $\mathrm{Fe} / \mathrm{Al}$ oxides, organic matter, the type and the $\mathrm{pH}$ value of the extractant, as well as the hydrophobicity of analytes, will ultimately determine the recoveries of both analytes.

\subsection{Method validation}

Under the conditions optimized above, method performance was evaluated with spiked soils. Satisfactory linearity was achieved over the range of $0.01-1 \mathrm{mg} \mathrm{L}^{-1}$ with correlation coefficients $\left(\mathrm{r}^{2}\right)$ that ranged from 0.9917 to 0.9998 and from 0.9968 to 1.000 for DPAA and PAA, respectively, as presented in Tables 3 and 4 . Table 5 shows the accuracy and precision which were evaluated by recovery experiments in one selected soil (Luvisol) spiked at two fortification levels (20 and $50 \mathrm{mg} \mathrm{kg}^{-1}$ ) after extraction. Accuracy was in the ranges of 3.0$5.5 \%$ and $2.4-7.0 \%$ for DPAA and PAA, respectively, and the intraday $(n=5)$ and interday $(n=5)$ precision were within the ranges from 1.3 to $5.0 \%, 2.0$ to $3.4 \%$ for DPAA and from 1.4 to $3.7 \%, 2.5$ to $2.9 \%$ for PAA, respectively. The detection limits (LODs) taken as 3 times the signal-to-noise ratio after 11 times of continuous injection, were about $0.01 \mu \mathrm{g} \mathrm{L}^{-1}$ for DPAA and $1.00 \mu \mathrm{g} \mathrm{\textrm {L } ^ { - 1 }}$ for PAA. The

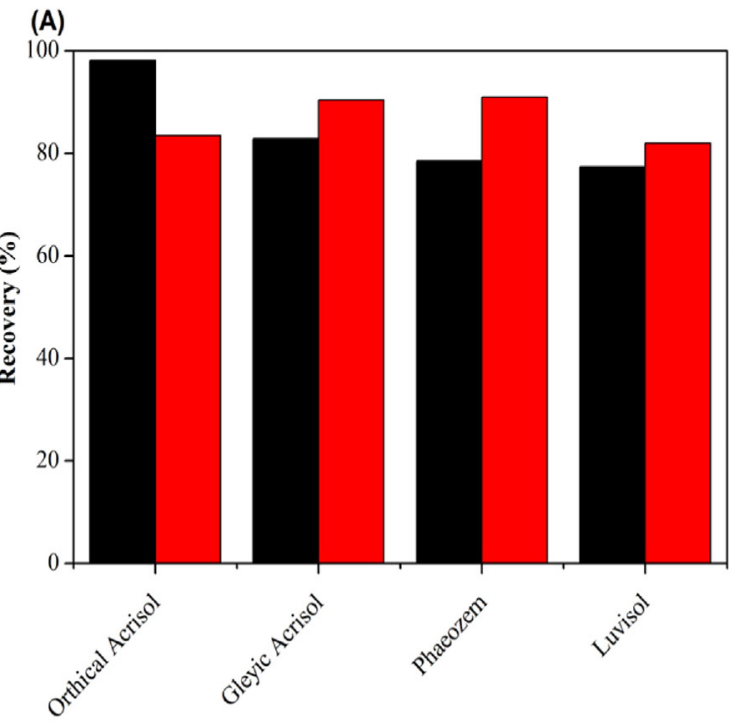

(B)

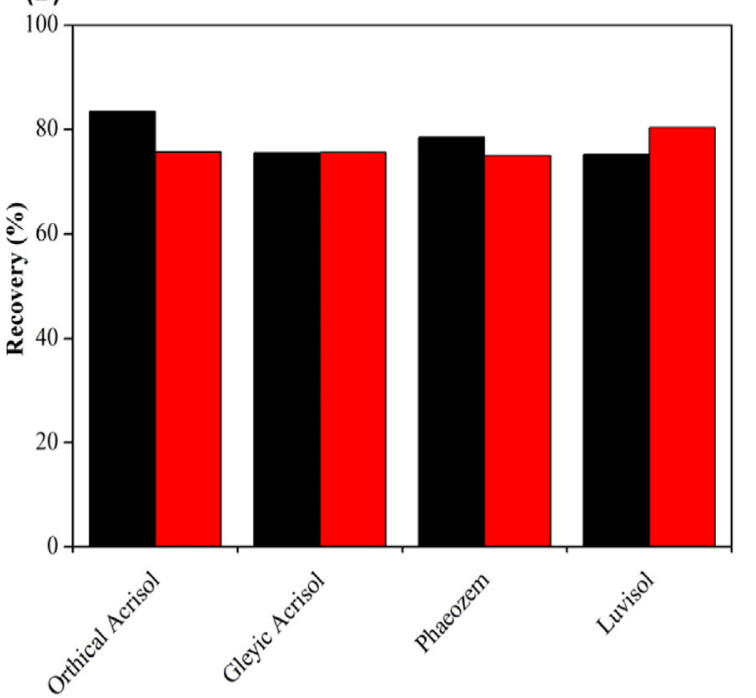

$20 \mathrm{mg} \mathrm{kg}^{-1} \square 50 \mathrm{mg} \mathrm{kg}^{-1}$

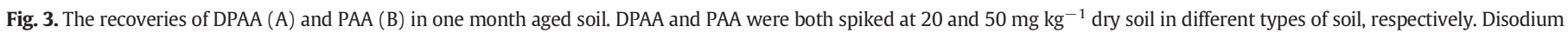

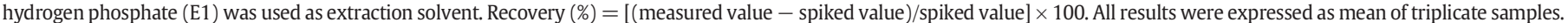


method detection limits (MDLs) obtained ranged from 2.52 to $3.42 \mu \mathrm{g} \mathrm{kg}^{-1}$ for DPAA and from 0.23 to $0.33 \mathrm{mg} \mathrm{kg}^{-1}$ for PAA depending on the soil types with disodium hydrogen phosphate extraction in the present study.

The proposed method was applied to the analysis of long-term contaminated soil. As is shown in Fig. 3, the recoveries of DPAA and PAA were in the range from 77.4 to $98.13 \%$ and 74.03 to $83.51 \%$ for DPAA and PAA in one month aged soils, respectively. According to the results obtained above, it is concluded that the proposed method is reliable.

\section{Conclusions}

A HPLC-MS/MS method was developed for determination of DPAA and PAA in soil. By optimizing the extraction procedure and the measurement conditions, simultaneous extraction, separation and quantification of DPAA and PAA were achieved and validated. Disodium hydrogen phosphate extraction provided the limited matrix effect $(102 \% \leq \mathrm{ME} \leq 115 \%)$ for both analytes $(n=4)$ together with satisfactory recoveries ranging between 73 and 109\% at two spiking levels (20 and $50 \mathrm{mg} \mathrm{kg}^{-1}$ ). In this approach, selection of an appropriate extractant as a simple, cost-effective and novel strategy for reducing matrix effects was demonstrated, to provide an analytical methodology for investigation of environmental contamination of soil by DPAA and PAA.

\section{Acknowledgements}

We wish to thank the National Natural Science Foundation of China (Project 41230858 and 41571310) for financial support. We also thank Dr. Ying Liu for the assistance with HPLC-MS/MS analysis, and Prof. Alice Newton for the English language revision.

\section{References}

Alam, M.G.M., Tokunaga, S., Maekawa, T., 2001. Extraction of arsenic in a synthetic arsenic-contaminated soil using phosphate. Chemosphere 43, 1035-1041.

Arao, T., Maejima, Y., Baba, K., 2009. Uptake of aromatic arsenicals from soil contaminated with diphenylarsinic acid by rice. Environ. Sci. Technol. 43 (4), 1097-1101.

Baba, K., Arao, T., Maejima, Y., Watanabe, E., Eun, H., Ishizaka, M., 2008. Arsenic speciation in rice and soil containing related compounds of chemical warfare agents. Anal. Chem. 80, 5768-5775.

Chen, L., Song, F.R., Liu, Z.Q., Zhong, Z., Xing, J.P., Liu, S.Y., 2014. Study of the ESI and APCI interfaces for the UPLC-MS/MS analysis of pesticides in traditional Chinese herbal medicine. Anal. Bioanal. Chem. 406, 1481-1491.

Daus, B., Mattusch, J., Wennrich, R., Weiss, H., 2008. Analytical investigations of phenyl arsenicals in groundwater. Talanta 75 (2), 376-379.

Deng, H.M., Evans, P.O.M., 1997. Social and environmental aspects of abandoned chemical weapons in China. Nonprol. Rev. 4, 101-108.

Enke, C.G., 1997. A predictive model for matrix and analyte effects in electrospray ionization of singly-charged ionic analytes. Anal. Chem. 69, 4885-4893.

Fang, G.Z., Chen, J., Wang, J.P., He, J.X., Wang, S., 2010. N-Methylimidazolium ionic liquidfunctionalized silica as a sorbent for selective solid-phase extraction of 12 sulfonylurea herbicides in environmental water and soil samples. J. Chromatogr. A 1217, 1567-1574.

FAO-UNESCO, 1981. Soil map of the World, Volume V Europe, 1: 5000000 . FAO, Rome.

Guan, L., Hisatomi, S., Fujii, K., Nonaka, M., Harada, N., 2012. Enhanced transformation of diphenylarsinic acid in soil under sulfate-reducing conditions. J. Hazard. Mater. 241-242, 355-362.
Guan, L., Harada, N., Ono, Y., Takahashi, T., Fujii, K., Liu, X.L., Nanaka, M., 2013. Effects of diphenylarsinic acid on bacterial and archaeal community structures in an anaerobic paddy soil. Geoderma 195-196, 243-250.

Haas, R., Schmidt, T.C., Steinbach, K., Von Löw, E., 1998. Chromatographic determination of phenylarsenic compounds. Fresenius J. Anal. Chem. 361 (3), 313-318.

Hanaoka, S., Nagasawa, E., Nomura, K., Yamazawa, M., Ishizaki, M., 2005. Determination of diphenylarsenic compounds related to abandoned chemical warfare agents in environmental samples. Appl. Organometal. Chem. 19, 265-275.

Ishizaki, M., Yanaoka, T., Nakamura, M., Hakuta, T., Ueno, S., Komuro, M., Shibata, M., Kitamura, T., Honda, A., Doy, M., Ishii, K., Tamaoka, A., Shimojo, N., Ogata, T., Nagasawa, E., Hanaoka, S., 2005. Detection of bis(diphenylarsine)oxide, diphenylarsinic acid and phenylarsonic acid, compounds probably devired from chemical warfare agents, in drinking well water. J. Health Sci. 51, 130-137.

Kahakachchi, C., Uden, P.C., Tyson, J.F., 2004. Extraction of arsenic species from spiked soils and standard reference materials. Analyst 129, 714-718.

Kinoshita, K., Shida, Y., Sakuma, C., Ishizaki, M., Kiso, K., Shikino, O., Ito, H., Morita, M., Ochi, T., Kaise, T., 2005. Determination of diphenylarsinic acid and phenylarsonic acid, the degradation products of organoarsenic chemical warfare agents, in well water by HPLC-ICP-MS. Appl. Organomet. Chem. 19, 287-293.

Kloepfer, A., Quintana, J.B., Reemtsma, T., 2005. Operational options to reduce matrix effects in liquid chromatography-electrospray ionization spectrometry analysis of aqueous environmental samples. J. Chromatogr. A 1067, 153-160.

Li, S.X., Liu, W.X., Huang, Y.J., Teng, Y., Luo, Y.M., 2012. High performance liquid chromatography analyzing diphenylarsinic acid, a degradation product of chemical warfare agent in soil (in Chinese). Acta Pedologica Sin. 49, 394-397.

Liang, H.R., Foltz, R.L., Meng, M., Bennett, P., 2003. Ionization enhancement in atmospheric pressure chemical ionization and suppression in electrospray ionization between target drugs and stable-isotope-labeled internal standards in quantitative liquid chromatography/tandem mass spectrometry. Rapid Commun. Mass Spectrom. 17, 2815-2821.

Maejima, Y., Arao, T., Baba, K., 2011a. Transformation of diphenylarsinic acid in agricultural soils. J. Environ. Qual. 40, 76-82.

Maejima, Y., Murano, H., Iwafune, T., Arao, T., Baba, K., 2011b. Adsorption and mobility of aromatic arsenicals in Japanese agricultural soils. Soil Sci. Plant Nutr. 57, 429-435.

Matuszewski, B.K., Constanzer, M.L., Chavez-Eng, C.M., 1998. Matrix effect in quantitative LC-MS/MS analysis of biological fluids: a method for determincation of finasteride in human plasma at pictogram per milliliter concentration. Anal. Chem. 70, 882-889.

Matuszewski, B.K., Constanzer, M.L., Chavez-Eng, C.M., 2003. Strategies for the assessment of matrix effect in quantitative bioanalytical methods based on HPLC-MS/MS. Anal. Chem. 75, 3019-3030.

Mohapatra, D., Singh, P., Zhang, W., Pullammanappallil, P., 2005. The effect of citrate, oxalate, acetate, silicate and phosphate on stability of synthetic arsenic-loaded ferrihydrite and Al-ferrihydrite. J. Hazard. Mater. 124, 95-100.

Nakamiya, K., Yoshikane, M., Tomoko, H., Shibata, Y., 2013. Transformation of diphenylarsinic acid and related compounds in groundwater: production of thiolcontaining arsenicals. Environ. Chem. 10, 17-21.

Niessen, W.M.A., Manini, P., Andreoli, R., 2006. Matrix effect in quantitative pesticide analysis using liquid chromatography-mass spectrometry. Mass Spectrom. Rev. 25, 881-899.

Ochi, T., Suzuki, T., Isono, H., Kaise, T., 2004. In vitro cytotoxic and genotoxic effects of diphenylarsinic acid, a degradation product of chemical warfare agents. Toxicol Appl. Pharmacol. 200, 64-72.

Souverain, S., Rudaz, S., Veuthey, J.L., 2004. Matrix effect in LC-ESI-MS with off-line and on-line extraction procedures. J. Chromatogr. A 1058, 61-66.

Steen, R.J.A.C., Hogenboom, A.C., Leonard, P.E.G., Peerboom, R.A.L., Cofino, W.P., Brinkman, U.A.T., 1999. Ultra-level determination of polar pesticides and their transformation products in surface and esturine water samples using column liquid chromatography-electrospray tandem mass spectrometry. J. Chromatogr. A 857, 157-166.

Wang, A.N., Li, S.X., Teng, Y., Liu, W.X., Wu, L.H., Zhang, H.B., Huang, Y.J., Luo, Y.M., 2013. Adsorption and desorption of diphenylarsinicals in two contrasting soils. J. Environ. Sci. $25,1172-1179$.

Zheng, J., Yamada, M., Yoshida, S., 2011. Sensitive iodine speciation in seawater by multimode size-exclusion chromatography with sector-field ICP-MS. J. Anal. At. Spectrom. 26, 1785-1790.

Zuehlke, S., Duennbier, U., Heberer, T., 2004. Determination of polar drug residues in sewage and surface water applying liquid chromatography-tandem mass spectrometry. Anal. Chem. 76, 6548-6554. 